\title{
Universal properties of the dynamics of the Covid-19 pandemic
}

\author{
Piotr T. Chruściel ${ }^{* \dagger}$ Sebastian J. Szybka ${ }^{\dagger \dagger \ddagger}$
}

August 25, 2020

\begin{abstract}
We present evidence for existence of a universal lower bound for the initial growth rate of the epidemic curve of the SARS-CoV-2 coronavirus. This can be used to infer that, on average, an asymptomatic infected individual is infectious during $5.6 \pm 0.3$ days. We further present evidence of an average time scale of 12 days for halving the number of new cases, or new deaths, during the extinction period of the first phase of the epidemic.
\end{abstract}

\section{Contents}

1 Introduction

$\begin{array}{lll}2 & \text { The analysis } & 10\end{array}$

3 Conclusions $\quad 15$

$\begin{array}{ll}\text { A The growth rate } & 18\end{array}$

B $R_{0}$ for selected time-series $\quad 20$

C Remarks on the "double-logistic" function 22

\section{Introduction}

The development of strategies to fight future phases of the Covid-19 pandemic, or similar future epidemics, requires a good understanding of the global features of the evolution of the epidemic. In particular it is important to obtain quantitative information about the epidemic which is independent of the local conditions such as social habits of the local population or the details of the confinement measures. In this work we show existence of a universal lower bound on the rate of the initial growth of the epidemic, with a characteristic time scale of about 6 days. We argue that this minimal rate of growth can be explained by

\footnotetext{
*Faculty of Physics, University of Vienna

${ }^{\dagger}$ EmaIL piotr.chrusciel@univie.ac.at, URL homepage.univie.ac.at/piotr.chrusciel

${ }^{\dagger}$ Astronomical Observatory, Jagiellonian University

$\ddagger \ddagger$ Copernicus Center for Interdisciplinary Studies
} 
an infectiousness time of infected individuals of 6 days. Furthermore, we show that the epidemiological data exhibit an average extinction rate with a characteristic time scale of 12 days. The information should be useful for monitoring the development of the current epidemic for countries which are still in the first phase thereof, as well as that of an upcoming second wave, or future coronavirus epidemics.

Our results are based on fitting to the epidemiological time-series the curves

$$
I(t)=k \times \frac{1}{1+e^{-(\alpha-\beta)(t-\tau)}} \times \frac{1}{1+e^{-\beta(t-\sigma)}}, \quad k>0, \alpha>\beta>0,
$$

introduced in [1] (see also Appendix C), which describe surprisingly well the global features of the confirmed-cases time-series and death time-series for the first phase of the Covid-19 epidemic, whenever a fit to the data is available. Here one should keep in mind that in many countries the epidemic stabilised to a new rampant phase, or entered a new growing phase, in which case the fits of the function $I$ to the data are becoming worse with time. This allows us to determine, for each time-series, the end of the first phase of the epidemic defined as the day for which the fit of the curve is optimal.

A shortcoming of the curve (1.1) is that $I$ can only provide a good fit for data sets for which the extinction rate is smaller than half of the initial growing rate; this is explained in Appendix A. While this is a fundamental bias of our analysis, it turns out that many Covid-19 time-series have this property. ${ }^{1}$

A key feature of the function $I$ is that if both $e^{(\alpha-\beta) \tau}$ and $e^{\beta \sigma}$ are sufficiently large, ${ }^{2}$ then near $t=0$ the function $I$ is well approximated by

$$
I(t) \approx c e^{\alpha t},
$$

where $c=k e^{-(\alpha-\beta) \tau-\beta \sigma}$. This shows that the parameter $\alpha$ carries information about the initial rate of growth of the epidemic.

Next, for large positive $t$ the function $I$ behaves as

$$
I(t) \approx k\left(1-C e^{-\beta t}\right),
$$

whenever $C=e^{\beta \sigma}$ or $t$ (or both) are sufficiently large. This shows that $\beta$ describes the extinction rate of the epidemic.

Fitting the curve to the time series of the epidemic for a given city, county, province, state, or country, provides quantitative information about the dynamics of the epidemic.

We have attempted to determine the parameters $(\alpha, \beta, k, \tau, \sigma)$ for all timeseries of the epidemic available at the John Hopkins University (JHU) server on July 1, 2020. As already pointed-out in [1], optically satisfactory fits to the time series of the curve (1.1) can be found for essentially all time-series that we have examined; several examples can be found below, in [1], and in the supplementary materials to this paper. However, it appears that satisfactory fits, in the sense

\footnotetext{
${ }^{1}$ This should be compared with the logistic function, where both the initial growth rate and the extinction rate are the same; the Gauss-error function, where both the growth and extinction rates vanish; and the Richards curve [2], where the initial and extinction rates are arbitrary but the growth amplitude is correlated with the extinction amplitude.

${ }^{2}$ For example, if both $e^{(\alpha-\beta) \tau} \geq 9$ and $e^{\beta \sigma} \geq 9$, then the relative error in (1.2) less than 10\%: $1 / x-1 /(1+x)=1 /(x(1+x)) \leq 0.1 \times 1 / x$ if $x \geq 9$. The accuracy of the approximation grows with growing $x$.
} 
of small residuals and decent standard deviations for the fit parameters, can typically only be found after the (first) peak of the number of new cases of epidemic. Moreover, wobbly time-series, or time series with jumps, often do not lead to fits which are satisfactory in this sense either. While our observations below are based on the time series with satisfactory fits, we checked that they are consistent with all fits when the large uncertainties of the parameters of the remaining fits are taken into account.

The values of all fitting parameters depend upon the country considered for many obvious reasons, such as awareness of the epidemic, quarantine measures taken, social habits of the local population, etc. The main observation of this work is the existence of absolute lower bounds for the constants $\alpha$ and $\beta$, independently of local factors. As reported in more detail in Section 2, we find the following lower bounds for all time-series examined:

$$
\alpha \geq \alpha_{\min }=0.124 \pm 0.006, \quad \beta \geq 0.016 \pm 0.009,
$$

with the minimum for $\alpha$ attained at the time series of the county Cumberland, New Jersey in the US, and the minimum for $\beta$ attained for the State of Victoria in Australia. This is illustrated in Figure 1.1, with the fits for Cumberland and Victoria shown in Figures 1.2 and 1.3. (Unless explicitly indicated otherwise, error indicators are standard deviations.)

For the death time-series the lower bounds on the corresponding parameters are rather similar:

$$
\alpha \geq \alpha_{\text {min }, \text { deaths }}=0.125 \pm 0.006, \quad \beta \geq 0.023 \pm 0.002,
$$

attained on the time series of DuPage, Illinois for $\alpha$ and Snohomish, Washington for $\beta$. This is illustrated in Figure 1.4, with the fits for DuPage and Snohomish in Figure 1.5.

The parameter $\alpha$ is directly related to the initial doubling time of the epidemic, which will be denoted by $T_{2}$. For data sets for which the approximation (1.2) holds we obtain a common bound on the doubling time:

$$
T_{2}=\frac{\ln 2}{\alpha} \leq \frac{\ln 2}{\alpha_{\min }} \approx 5.6 \pm 0.3 \text { days } .
$$

Now, for some of our fits the approximation (1.2) breaks down, but the value of the doubling time $T_{2}$ can be found numerically using the explicit form of $I$ when the fitting parameters are used. This shifts the threshold (1.6) to the bound

$$
T_{2} \leq T_{2, \max } \approx 6.1 \text { days }
$$

attained for the time series of Cumberland, New Jersey, already seen in Figure 1.2 .

Next, for all fits (to be found in supplementary materials) we find

$$
0.047<\frac{\beta}{\alpha}<0.38
$$

with the lower bound attained on Mason, Washington, and the upper bound on Ireland (both seen in Figure 1.6). Note that the upper bound stays well clear of the 0.5 limit imposed by our fitting function. 
medRxiv preprint doi: https://doi.org/10.1101/2020.08.24.20181214; this version posted August 30, 2020. The copyright holder for this preprint (which was not certified by peer review) is the author/funder, who has granted medRxiv a license to display the preprint in It is made available under a CC-BY-NC-ND 4.0 International license .

average: $0.23016 \pm 0.00049$

minimum: 0.124

maximum: 1.21

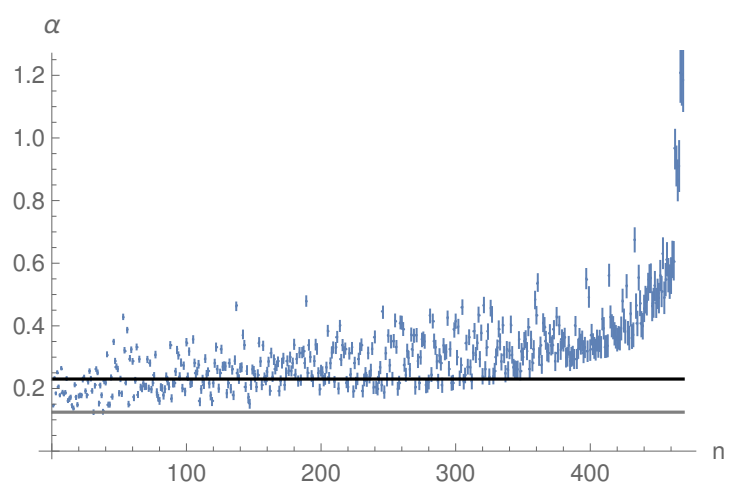

average: $0.052887 \pm 0.000055$

minimum: 0.0157

maximum: 0.268

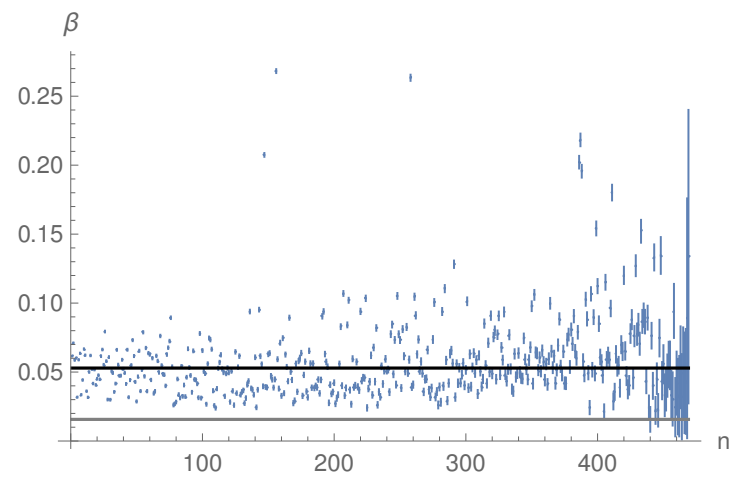

Figure 1.1: The values of the parameters $\alpha$ and $\beta$ for the confirmed-cases timeseries, ordered by increasing standard deviation. Only those fits where all relative errors of the fit are less than $10 \%$ were used in the analysis and are shown. The black line is the mean and the grey line is the minimum value. 


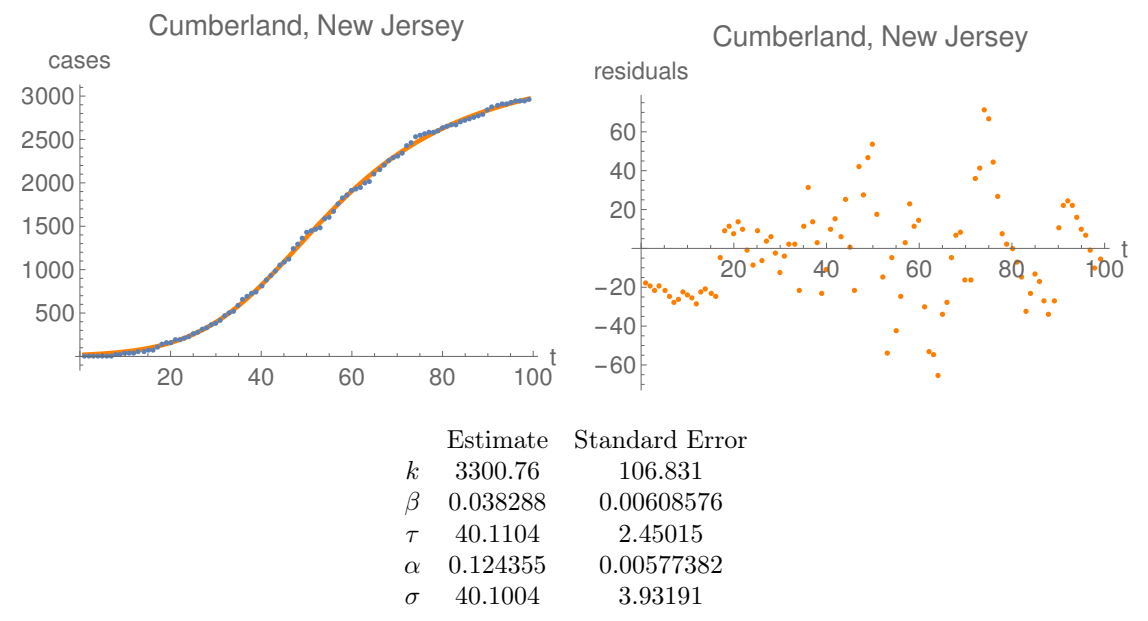

Figure 1.2: Plots of the time series and the best fit (left) before June 30, 2020, as well as the residuals of the fit (right) for the confirmed-cases time-series with smallest $\alpha$, namely Cumberland, New Jersey.

The average value of $\beta$ for all satisfactory fits is

$$
\beta \approx 0.057 \pm 0.003
$$

The corresponding average value for the death time-series is the same within standard deviation:

$$
\beta_{\text {deaths }} \approx 0.056 \pm 0.018 \text {. }
$$

This translates to an average time scale of twelve days for the halving of the number of new cases, or deaths, during the extinction period of the first phase of the epidemic.

The question arises about the origin of the lower bound on $\alpha$. Assuming that the number of confirmed cases during the first week or so of the epidemic is proportional to the number of infectious individuals and that the approximation (1.2) holds, we show in Appendix A that a precise lower bound $\alpha \geq \alpha_{\text {min }}$ determines a lower bound on the number of days, say $k_{0}$, during which an infected individual is infectious.

Supposing we had access to all possible curves for the epidemic, the threshold number $\alpha_{\min }$ would then be determined exactly from these curves. Now, we only have a set of 469 curves. Given that this is quite a large number, it appears reasonable to assume that the minimal value of $\alpha$ which we see in our fits is approximately equal to the threshold value $\alpha_{\min }$. This, together with (1.4), leads to

$$
k_{0} \approx 6 \text { days }
$$

consistently with data obtained by completely different methods in $[3,4]$.

It should be pointed out that (1.11) applies to asymptomatic infected individuals, since the number of these is much larger than the number of symptomatic ones.

As further explained in the Appendix, for time series which are well approximated at the beginning by an exponential, the initial propagation number is 
medRxiv preprint doi: https://doi.org/10.1101/2020.08.24.20181214; this version posted August 30, 2020. The copyright holder for this preprint (which was not certified by peer review) is the author/funder, who has granted medRxiv a license to display the preprint in

It is made available under a CC-BY-NC-ND 4.0 International license .
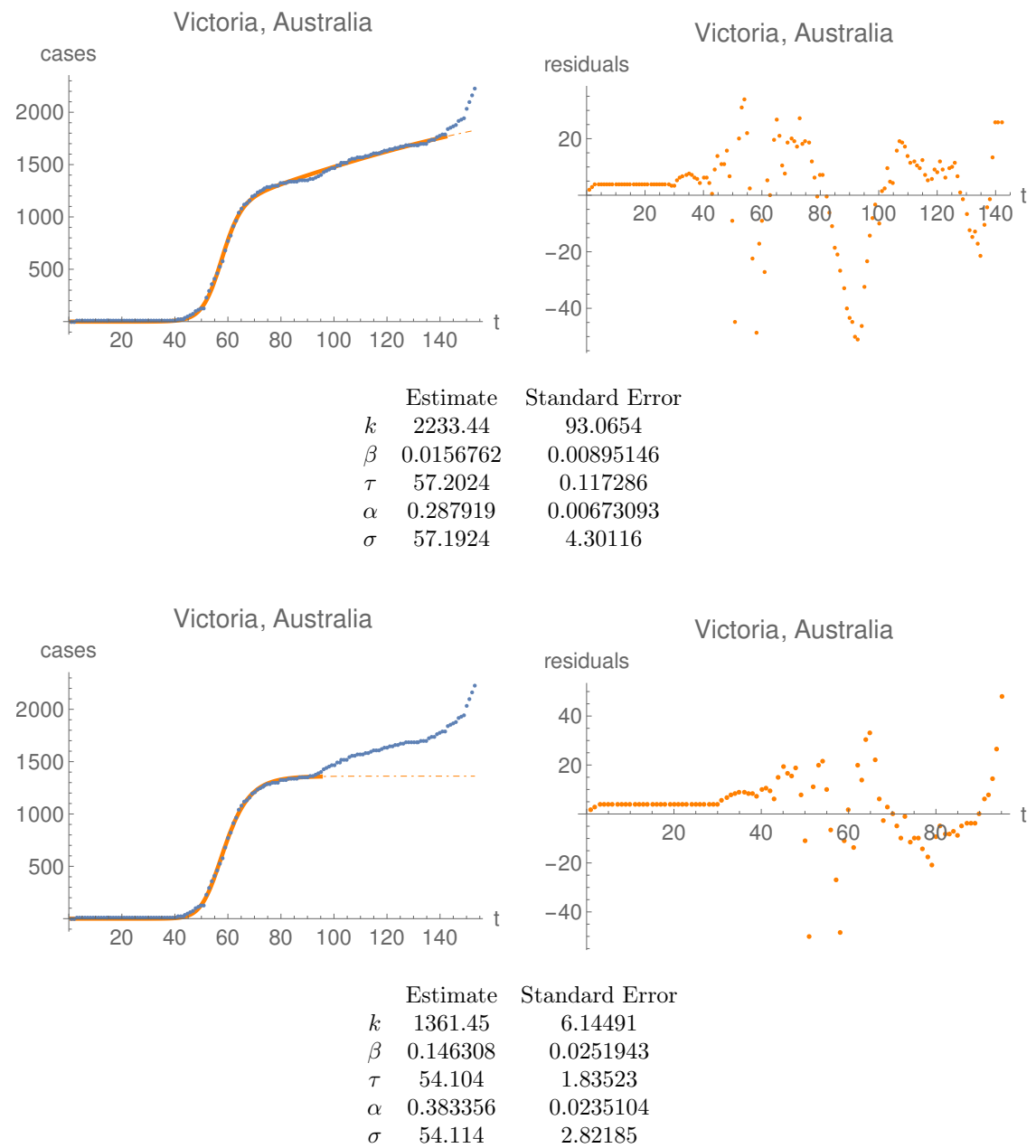

Figure 1.3: Plots of the time series and the best fit (left) before June 30, 2020, as well as the residuals of the fit (right) for the confirmed-cases time-series with smallest smallest $\beta$, namely the State of Victoria in Australia. Note the different scales for all plots. The data from the first plot for Victoria have been used for the analysis described in the main body of the paper. The second plot for Victoria has been fine-tuned by hand for a first phase which stops around day 82 (May 3), with optically more satisfactory residuals but with a worse "goodness parameter" ( $19.3 \%$ for the first plot and $24.3 \%$ for the second). Note that $\tau$ and $\sigma$ are very close to each other for both plots, and we have found such fits unstable and therefore unreliable. 
medRxiv preprint doi: https://doi.org/10.1101/2020.08.24.20181214; this version posted August 30, 2020. The copyright holder for this preprint (which was not certified by peer review) is the author/funder, who has granted medRxiv a license to display the preprint in

perpetuity.
It is made available under a CC-BY-NC-ND 4.0 International license .

average: $0.22309 \pm 0.00076$

minimum: 0.125

maximum: 0.722

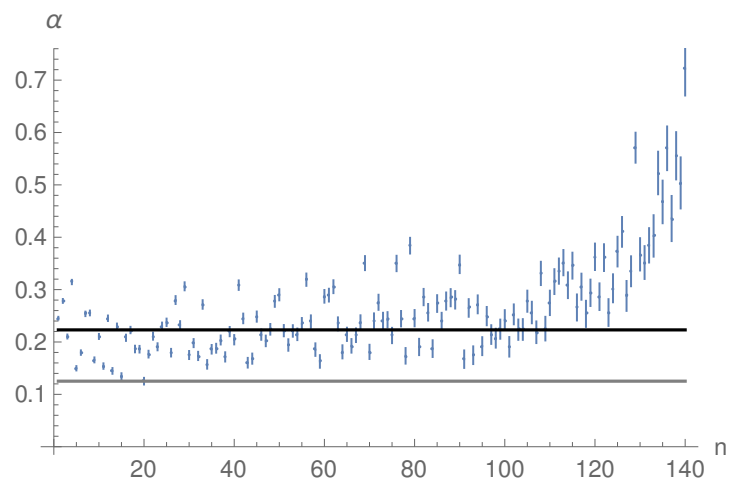

average: $0.059764 \pm 0.00013$

minimum: 0.023

maximum: 0.114

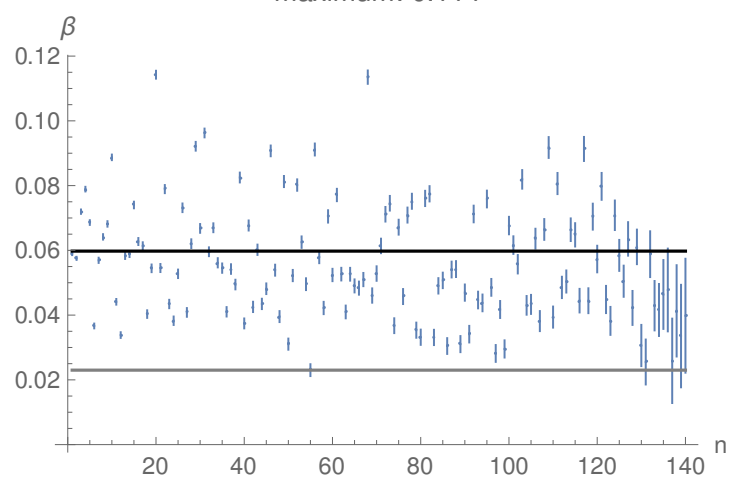

Figure 1.4: The values of the parameters $\alpha$ and $\beta$ for the deaths time-series, ordered by increasing standard deviation. The black line is the mean and the grey line is the minimum The averages indicated here are weighted with the standard deviation, while the ones indicated in the text are the straightforward ones. 
medRxiv preprint doi: https://doi.org/10.1101/2020.08.24.20181214; this version posted August 30, 2020. The copyright holder for this preprint (which was not certified by peer review) is the author/funder, who has granted medRxiv a license to display the preprint in It is made available under a CC-BY-NC-ND 4.0 International license .
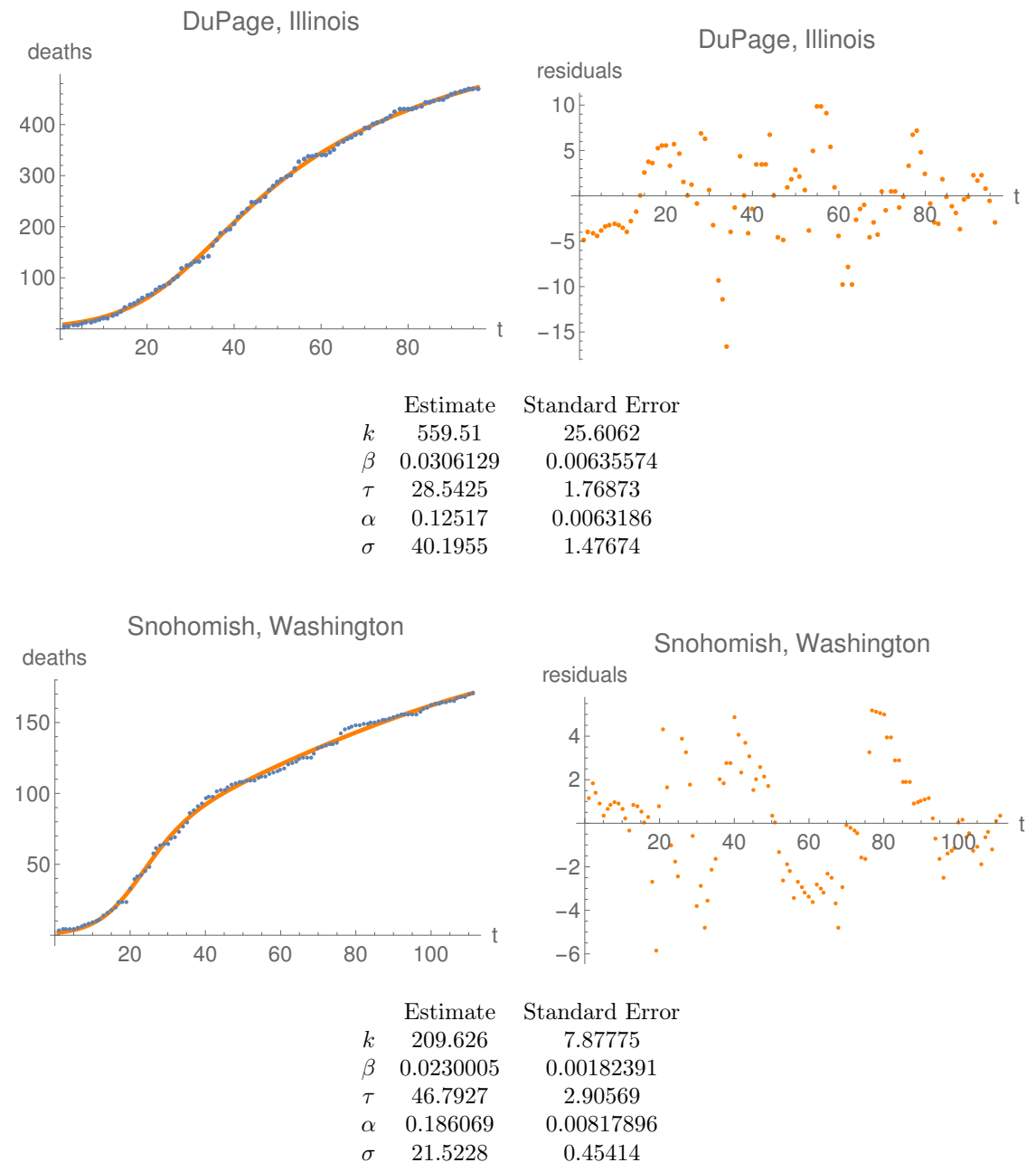

Figure 1.5: Plots of the time series and the best fit (left) before June 30, 2020, as well as the residuals of the fit (right) for the deaths time-series with smallest $\alpha$, namely DuPage, Illinois, and smallest $\beta$, i.e. Snohomish, Washington. Note the different scales for all plots. Both time series end on June 30, and start at the day at which more than one death has been registered. 
medRxiv preprint doi: https://doi.org/10.1101/2020.08.24.20181214; this version posted August 30, 2020. The copyright holder for this preprint (which was not certified by peer review) is the author/funder, who has granted medRxiv a license to display the preprint in It is made available under a CC-BY-NC-ND 4.0 International license .
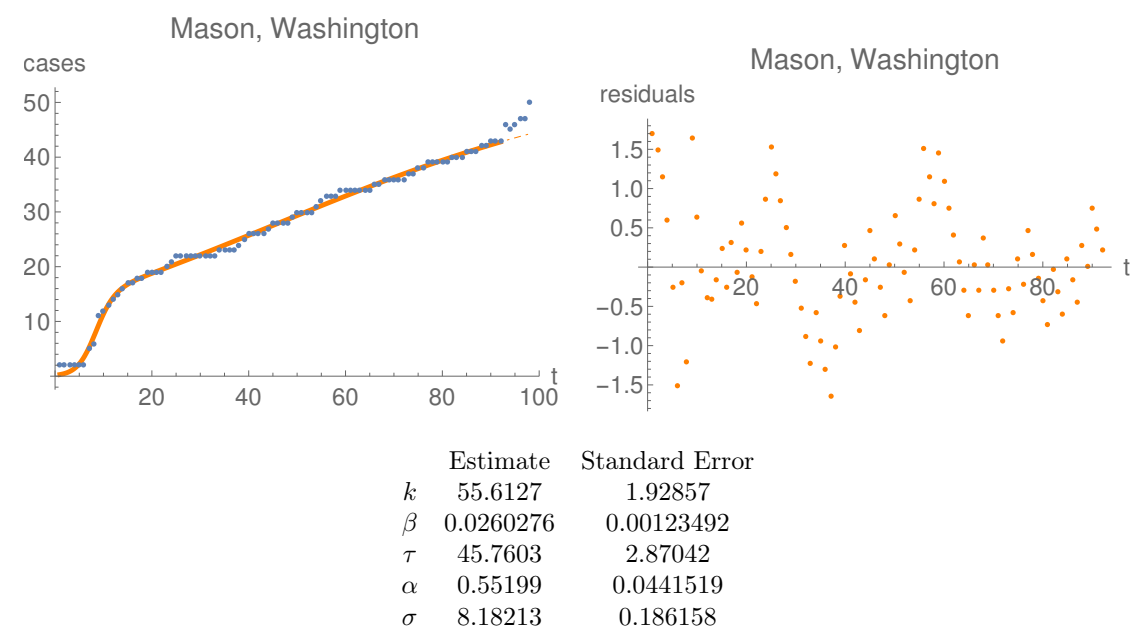

Standard Error

1.92857

0.00123492

2.87042

0.0441519

0.186158

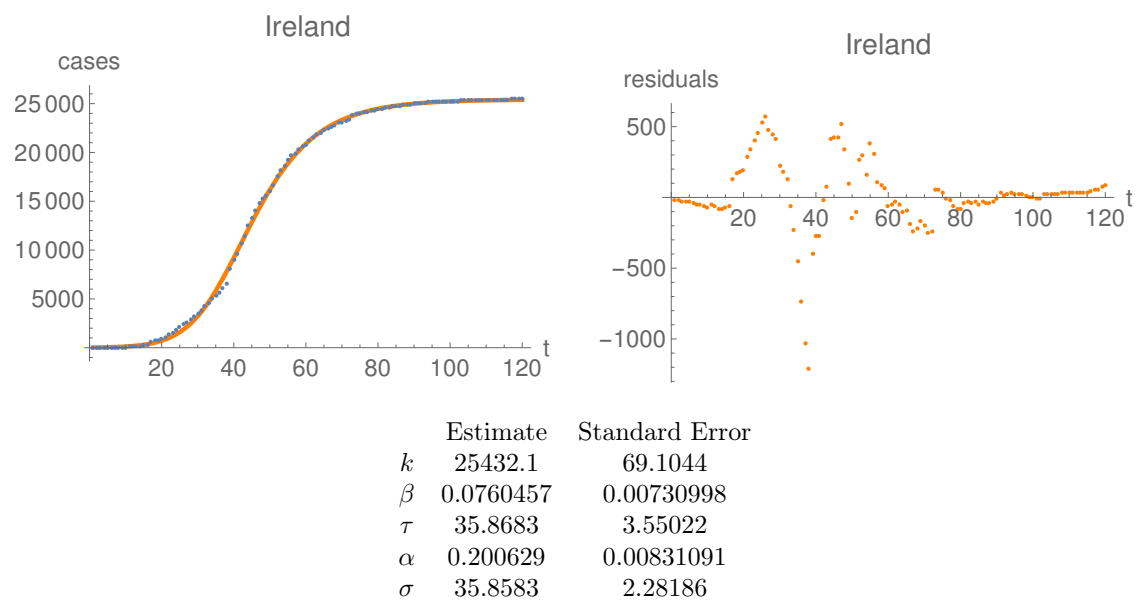

Figure 1.6: Plots of the time series and the best fit (left) before June 30, 2020, as well as the residuals of the fit (right) for the confirmed-cases time-series with smallest ratio $\beta / \alpha$ (for Mason, Washington) and largest ratio $\beta / \alpha$ (for Ireland). Note the different scales for all plots. 


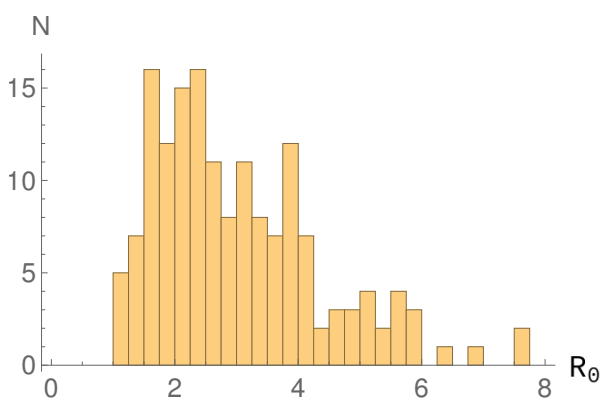

Figure 1.7: Histogram of those values of $R_{0}$ which have a standard deviation less than $10 \%$ truncated at 8 ; see the Table B.1, Appendix B for the three missing fits beyond 8 .

determined by the equation

$$
R_{0}=e^{\alpha \ln (2) / \alpha_{\min }}-1=2^{\alpha / \alpha_{\min }}-1
$$

(see Equation (A.3)). This, together with (1.11), allows us to determine $R_{0}$ for each time-series with a satisfactory fit.

In what follows we only consider the 145 fits for which the values of $R_{0}$ have a standard deviation less than $10 \%$. The histogram of the resulting distribution of $R_{0}$ can be found in Figure 1.7. We find

$$
R_{0} \in(1,13.5 \pm 1.2]
$$

with an average

$$
R_{0, \mathrm{avg}}= \begin{cases}1.97 \pm 0.01, & \text { (weighted) } \\ 3.18 \pm 1.8, & \text { (direct) }\end{cases}
$$

The weighted average is calculated by weighing with the standard deviation of $R_{0}$ of the individual time-series, while the direct average is the obvious one.

The minimum value $R_{0}=1$ is attained for the county Cumberland in New Jersey, and the maximum value $R_{0}=13.5 \pm 1.2$ in (1.13) is attained for the county of Stearns in Minnesota, with fits shown in Figure 1.8 The values of $R_{0}$ so determined are provided in Table 1.1 for a sample of countries. A table presenting the values of $R_{0}$ for all satisfactory fits with relative error of $R_{0}$ less than $10 \%$ can be found in Appendix B.

\section{The analysis}

We analysed the time series for confirmed cases, confirmed US cases, deaths and US deaths as available on the John Hopkins University server on July 1, 2020. After ignoring all time-series which have less than two cases on June 30, as well as the US time-series which appear as "Unassigned" and "Out of ...", we were left with 3149 confirmed-cases time-series and 1647 deaths time-series.

These time series include whole countries, but also time series for e.g. French Domaines d'Outre Mer - Territoires d'Outre Mer, or for each Australian State, or for each Chinese Province, or for US counties. 
medRxiv preprint doi: https://doi.org/10.1101/2020.08.24.20181214; this version posted August 30, 2020. The copyright holder for this preprint (which was not certified by peer review) is the author/funder, who has granted medRxiv a license to display the preprint in

It is made available under a CC-BY-NC-ND 4.0 International license .
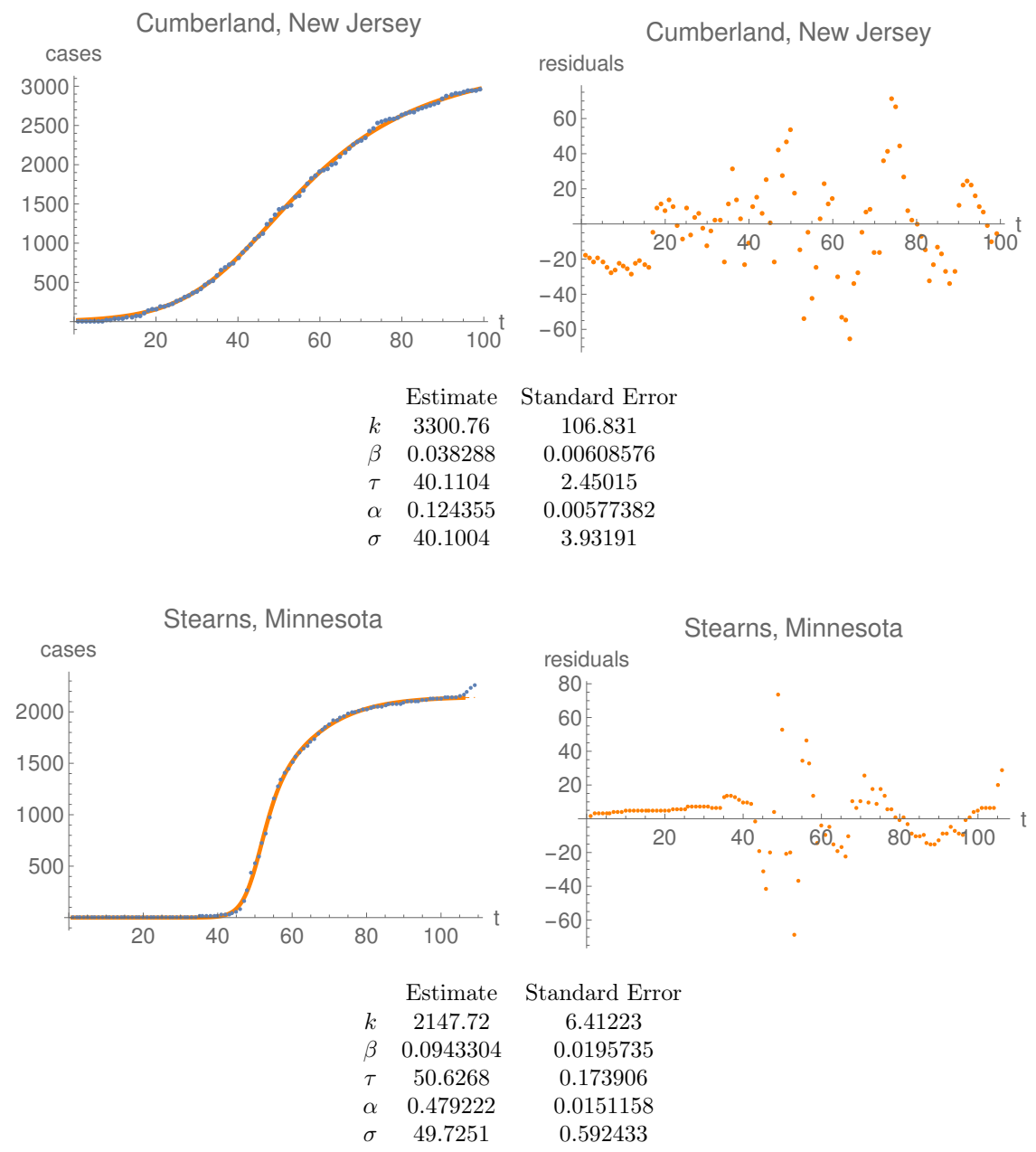

Figure 1.8: Plots of the time series and the best fit (left) before June 30, 2020, as well as the residuals of the fit (right) for the confirmed-cases time-series with the smallest (Cumberland, New Jersey) and largest (Stearns, Minnesota) value of $R_{0}$. Note the different scales for all plots. 
medRxiv preprint doi: https://doi.org/10.1101/2020.08.24.20181214; this version posted August 30, 2020. The copyright holder for this preprint (which was not certified by peer review) is the author/funder, who has granted medRxiv a license to display the preprint in It is made available under a CC-BY-NC-ND 4.0 International license .
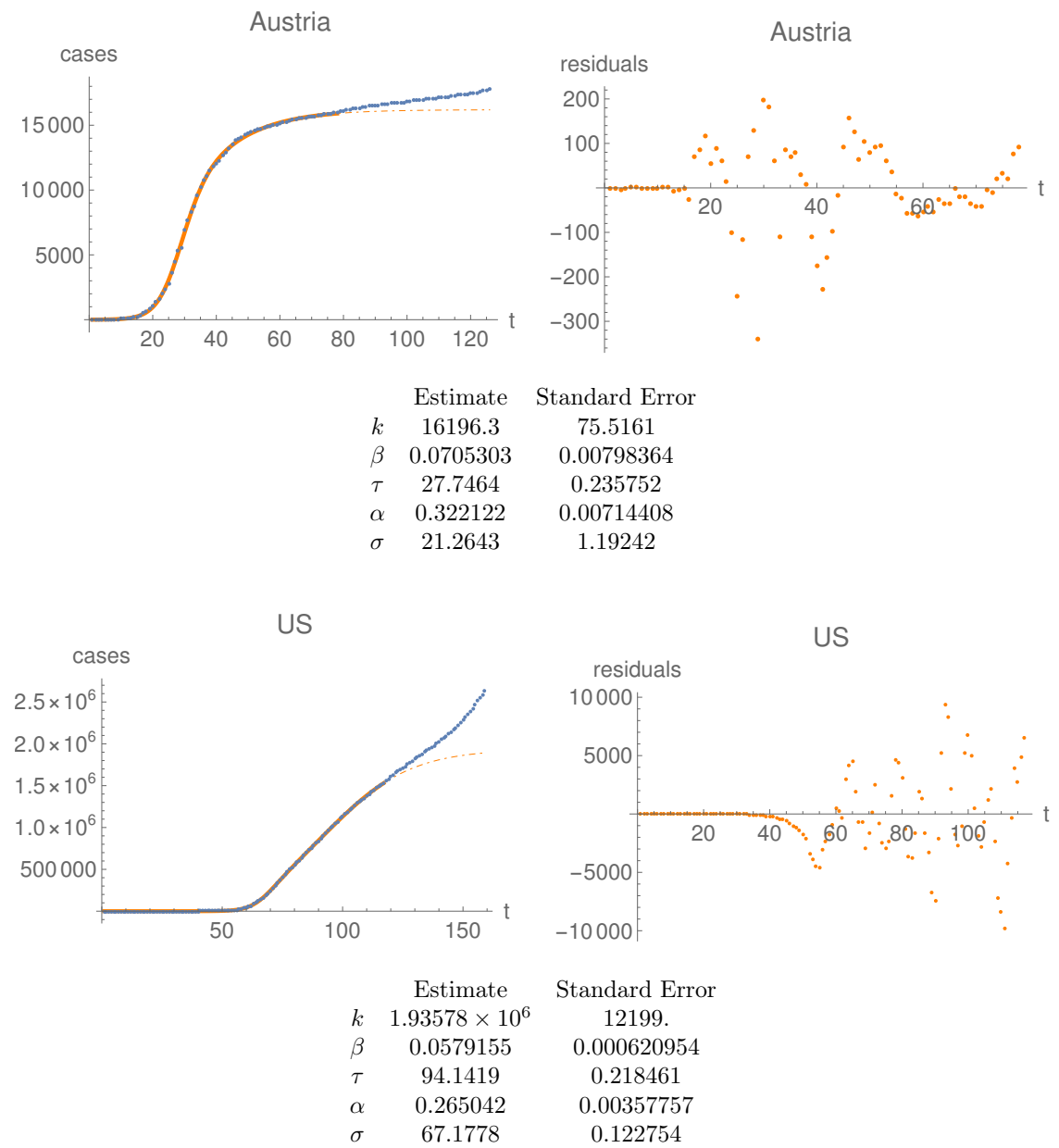

Figure 1.9: Plots of the time series and the best fit (left) before June 30, 2020, as well as the residuals of the fit (right) for the confirmed-cases time-series for Austria and for the US. Note the different scales for all plots. 


\begin{tabular}{|l|l|l|l|l|l|l|l|l|}
\hline & Country & $\mathrm{R}_{0}$ & & Country & $\mathrm{R}_{0}$ & & Country & $\mathrm{R}_{0}$ \\
\hline 1 & Austria & $5.02 \pm 0.24$ & 9 & Germany & $2.67 \pm 0.06$ & 17 & Netherlands & $4.8 \pm 0.5$ \\
\hline 2 & Belgium & $1.85 \pm 0.07$ & 10 & Greece & $1.92 \pm 0.09$ & 18 & Poland & $1.86 \pm 0.07$ \\
\hline 3 & Croatia & $5.5 \pm 0.5$ & 11 & Hungary & $1.51 \pm 0.07$ & 19 & Romania & $2.63 \pm 0.11$ \\
\hline 4 & Cyprus & $3.00 \pm 0.25$ & 12 & Ireland & $2.06 \pm 0.14$ & 20 & Spain & $2.56 \pm 0.11$ \\
\hline 5 & Czechia & $2.71 \pm 0.13$ & 13 & Italy & $3.07 \pm 0.07$ & 21 & Sweden & $1.24 \pm 0.06$ \\
\hline 6 & Denmark & $1.29 \pm 0.06$ & 14 & Latvia & $3.94 \pm 0.21$ & 22 & United Kingdom & $2.72 \pm 0.11$ \\
\hline 7 & Estonia & $2.27 \pm 0.20$ & 15 & Lithuania & $2.13 \pm 0.16$ & 23 & US & $3.38 \pm 0.09$ \\
\hline 8 & Finland & $2.12 \pm 0.14$ & 16 & Luxembourg & $5.9 \pm 0.4$ & & & \\
\hline
\end{tabular}

Table 1.1: A sample of values of the initial rate of propagation $R_{0}$, as determined using the double-logistic function. Strictly speaking, the numbers given are lower bounds for $R_{0}$, but we expect them to be close to the correct values. The fits for the extreme members of the table, namely Austria and the US, can be found in Figure 1.9.

For each such time-series we attempted to determine the day, say $T_{f}$, and the parameters $(\alpha, \beta, k, \tau, \sigma)$ so that the curve (1.1) fits optimally the data up to day $T_{f}$, using the NonlinearModelFit procedure in Mathematica. Finding a fit sometimes requires indicating parameters which are used as starting values for the fitting procedure, with fits depending upon the starting parameters. To take this into account we generated, for each time-series, a hundred random values of starting parameters, and from the collection of resulting fits we chose the "best fit". This "best fit" was determined by adding the values of the largest relative residual (defined as the ratio of the largest residual to the number of cases at the end of the time series) to the relative standard deviations of all five parameters of the fit, and choosing the fit for which the resulting number was smallest. We carried-out this analysis for time series truncated to April 16, then to April 17, etc., until June 30, and the day of the end of the first phase, say $T_{f}$, was determined by choosing the time series with the best fit on day $T_{f}$. All the satisfactory fits found had a date $T_{f}$ later than April 27 (with April 28 attained by the time series for Sichuan, China, seen in Figure 2.1.)

While the above results in optically satisfactory fits in most cases, some of the resulting fits have parameters with large standard deviations. To eliminate those we only kept the fits where the absolute value of the largest relative residual divided by the last value of the time series was smaller than $10 \%$, and where the relative standard deviations of each parameter were smaller than $10 \%$. All this led to 469 satisfactory fits for the confirmed-cases time-series, and 140 satisfactory fits for the deaths time-series.

In Figure 1.1 we show the resulting values of the parameters $\alpha$ and $\beta$ together with their standard errors, ordered by increasing length of confidence interval, for the confirmed-cases time-series. The figure shows clearly the lower bound of $\alpha$ of (1.4). Figure 2.2 shows the histograms of the values of $\alpha$ and $\beta$.

It follows from (1.2) that the larger the value of $\alpha$, the faster the initial growth of the epidemic. So the two time-series with smallest value of $\alpha$, namely Cumberland, New Jersey (see Figure 1.8) and San Juan, New Mexico (Figure 2.3) are the ones with the slowest initial growth of the epidemic. Likewise 


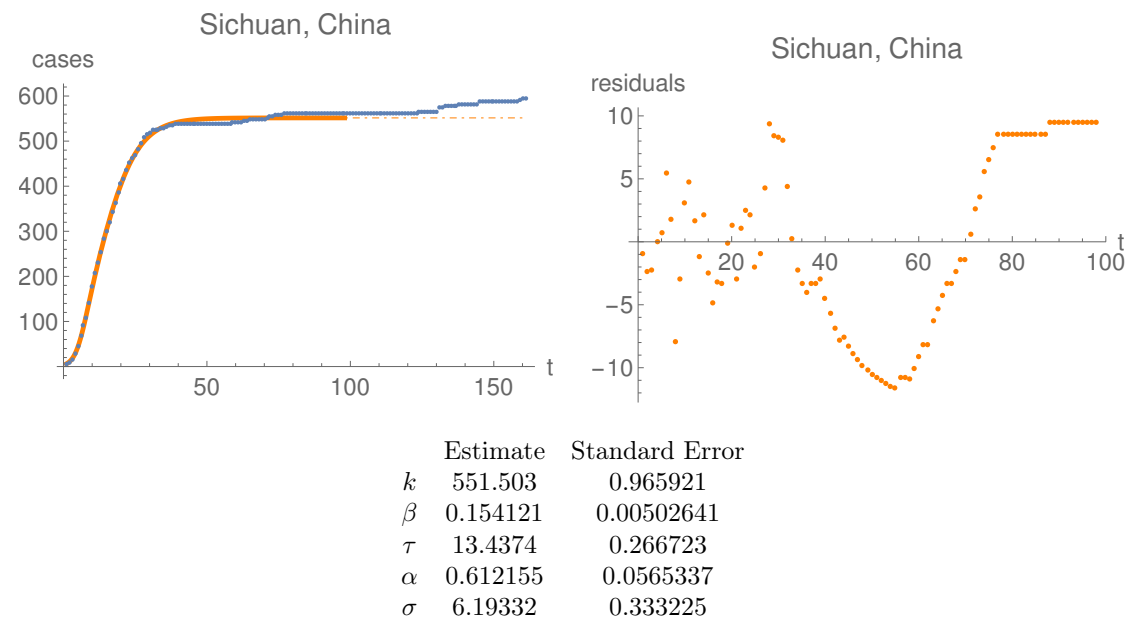

Figure 2.1: Plots of the time series and the best fit (left) before June 30, 2020, as well as the residuals of the fit (right) for the confirmed-cases time-series of Sichuan, China, which has the earliest date of the end of the first phase of the pandemic. Note the different scales for all plots.
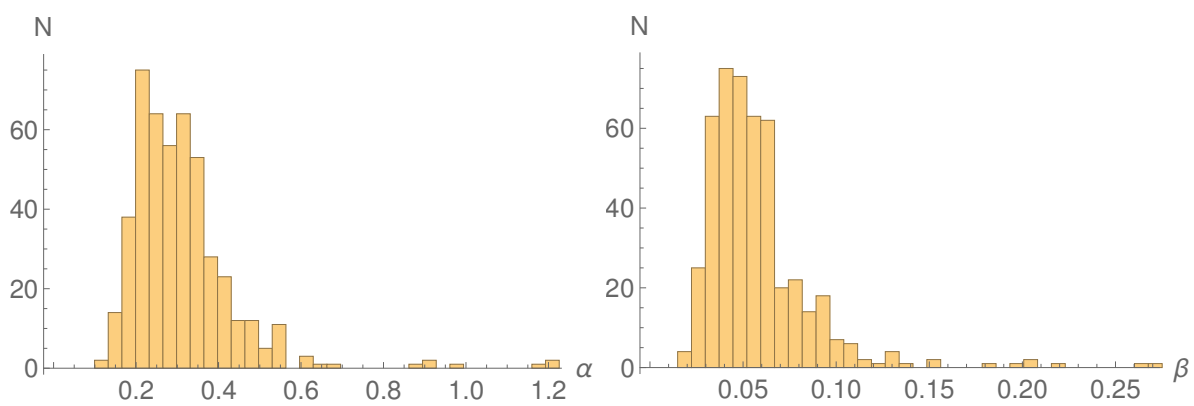

Figure 2.2: Histograms of the values of $\alpha$ (left) and $\beta$ (right) for the confirmedcases time-series.

the two time-series with largest values of $\alpha$, namely South Korea and Stearns, Minnesota, are the ones with fastest initial growth of the epidemic. The fits for these time series are shown in Figures 1.8 and 2.4.

The last data point on all plots is June 30, 2020.

We note that we only show in this paper the fits for the outliers of our analysis, which are not necessarily very good fits, and we hope that the reader will not draw the conclusion that no good fits can be obtained to the curve (1.1). In the supplementary material the reader will find the complete set of our fits, which hopefully should dispel such an impression. It should also be clear, by inspection of the fits presented here or in the supplementary materials, that the fits can be fine-tuned for individual time-series by removing outliers and other data manipulation, but we have not attempted to do this.

We have repeated the above analysis for the deaths time-series from the JHU server. Figure 1.4 illustrates the lower bound $\alpha \geq 0.125$ for these time series. 


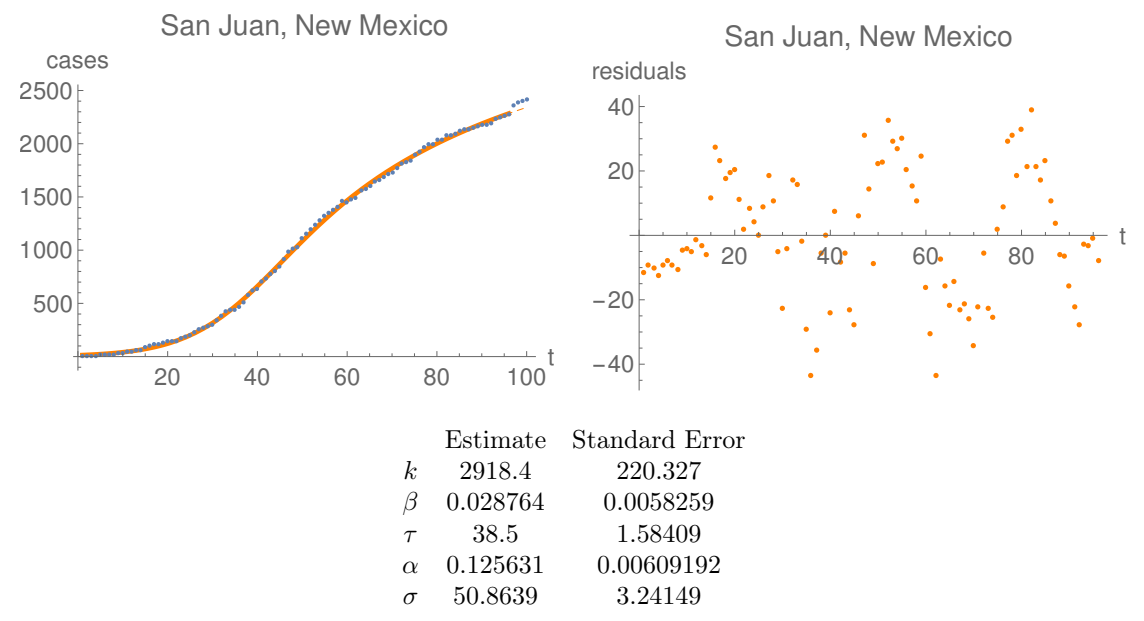

Figure 2.3: Plots of the time series and the best fit (left) before June 30, 2020, as well as the residuals of the fit (right) for the confirmed-cases time-series of San Juan, New Mexico, with the second smallest value of $\alpha$. Note the different scales for the plots.

The relevant histograms can be found in Figure 2.6. The lower bound for $\alpha$ is attained on the time series of DuPage, Illinois $(\alpha=0.125 \pm 0.006)$ with the next smallest value for Riverside, California $(\alpha=0.135 \pm 0.006)$. The two deaths time-series recording the fastest initial growth rate are Westchester, New York $(\alpha=0.57 \pm 0.03)$, and Nassau, New York $(\alpha=0.72 \pm 0.05)$. The four associated fits can be seen in Figures 1.5, 2.7 and 2.8.

In Figure 2.5 we show the values of $\alpha$ and $\beta$ for all fits for which the parameter errors are less than 100\%; the values of the parameters for such fits, when not in our previous list filtered to $10 \%$, should be interpreted with care. The plot shows that our lower bounds (1.4) are satisfied by an overwhelming majority of fits, including the poor ones.

\section{Conclusions}

We used the double-logistic curve of [1] to obtain quantitative information on the dynamics of the Covid-19 epidemics up to June 30, 2020. This curve approximates surprisingly well most of the time series until a date which we interpret as the end of the first phase of the epidemic, even when the fits are unsatisfactory from a mathematical point of view. In many cases the fact that the errors of the fitting parameters are large can be explained by a short time-series, or changes in the reporting procedures during the epidemic, or appearances of new clusters related to changes in confinement measures.

We have shown existence of a lower rate of the initial growth of the epidemics. We suggest that this lower bound can be used to determine the time during which an infected asymptomatic individual is infectious. This then allows one to determine the initial propagation number $R_{0}$ for time series with satisfactory fits to our curve. We have observed that the average extinction rate of the epidemics is about 12 days. 
medRxiv preprint doi: https://doi.org/10.1101/2020.08.24.20181214; this version posted August 30, 2020. The copyright holder for this preprint (which was not certified by peer review) is the author/funder, who has granted medRxiv a license to display the preprint in

It is made available under a CC-BY-NC-ND 4.0 International license .
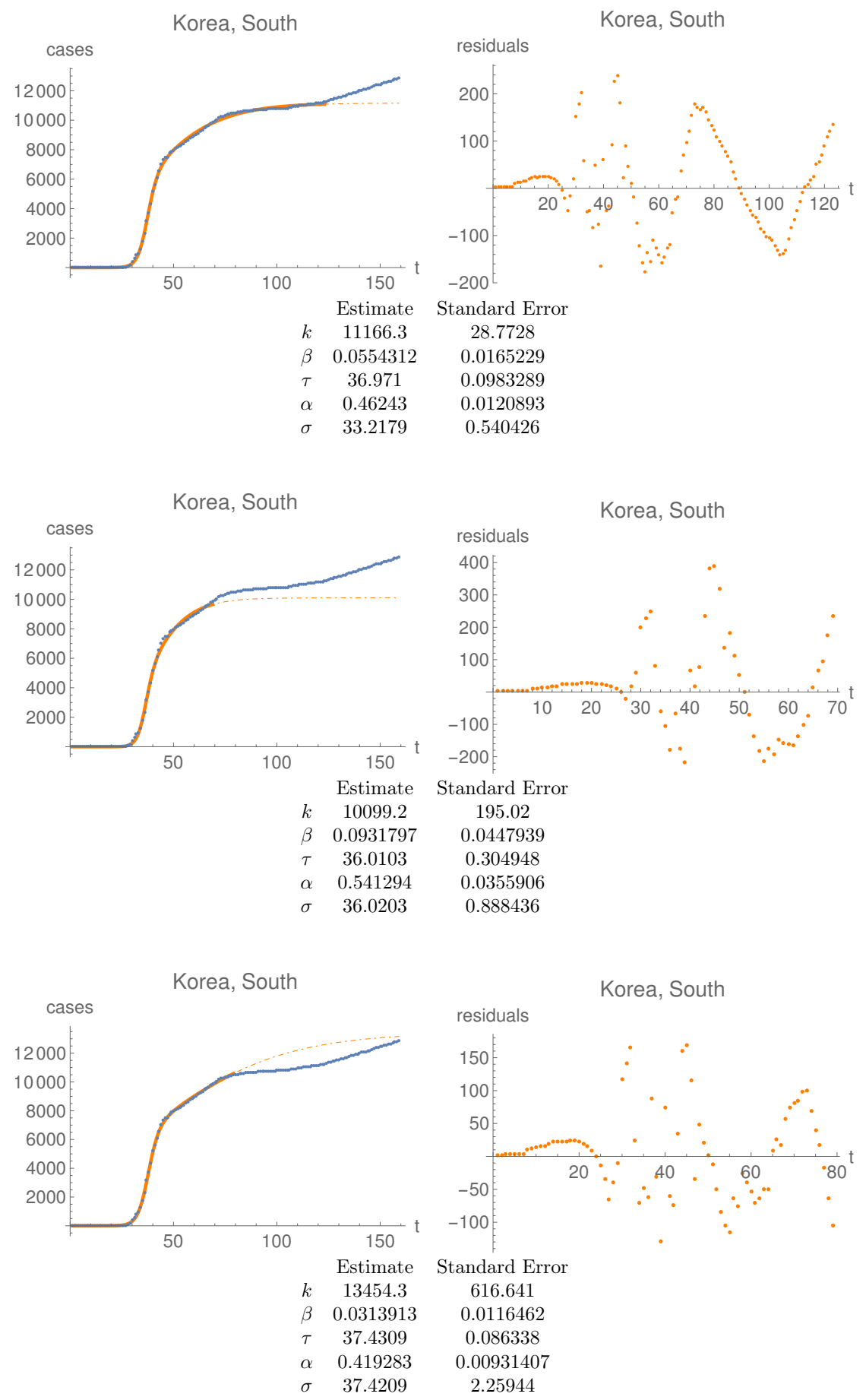

Figure 2.4: Data points, the best fit before June 30, 2020, and its residuals for South Korea. The first fit, automatically chosen by our algorithm and used for the analysis in the body of the paper, indicates existence of two phases, with the second one starting on May 26. The second fit has been fine-tuned by hand to find a second phase starting around day 50 of the epidemics; in this case the fit ends on April 1. The third fit ends on April 11 and has been found by the computer as one with the best goodness parameter for fits ending around the beginning of April. These two fits illustrate again that fits with very similar $\tau$ and $\sigma$ are unstable. One can wonder in any case whether any systematic studies based on our curve (1.1) apply to the time series of South Korea. 
medRxiv preprint doi: https://doi.org/10.1101/2020.08.24.20181214; this version posted August 30, 2020. The copyright holder for this preprint (which was not certified by peer review) is the author/funder, who has granted medRxiv a license to display the preprint in

It is made available under a CC-BY-NC-ND 4.0 International license .
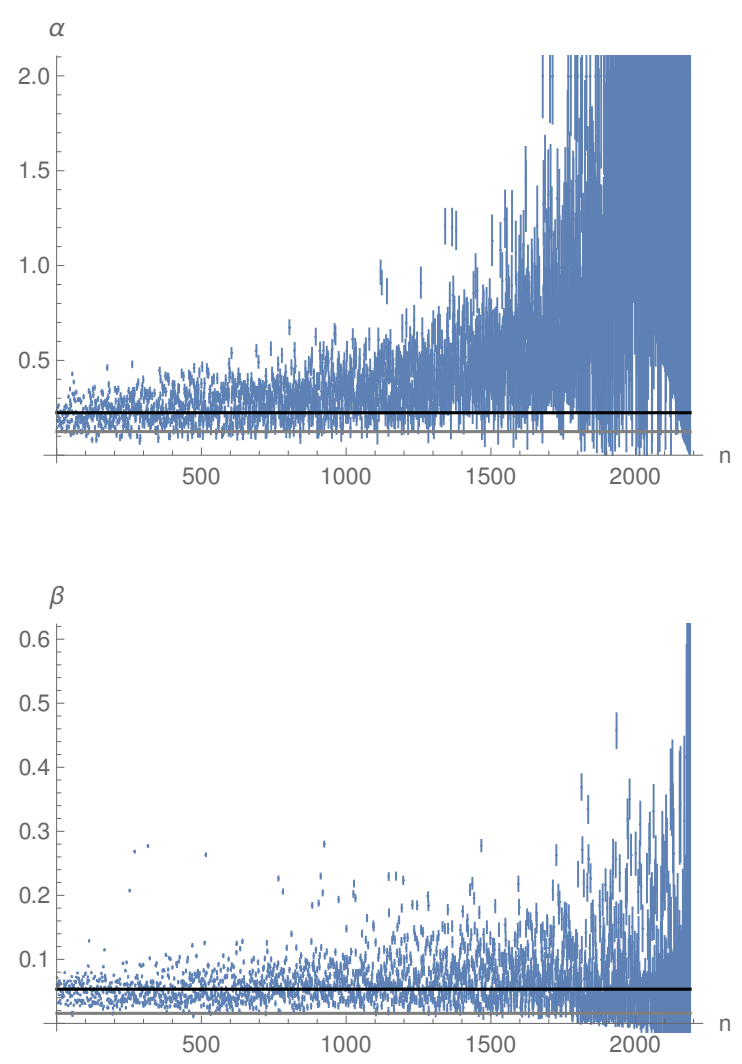

Figure 2.5: The values of the parameters $\alpha$ and $\beta$ for the confirmed-cases timeseries, ordered by increasing standard deviation, after rejecting fits with standard deviations larger than $100 \%$ on some parameter. The black line is the mean weighted by standard deviation and the grey lines are the value of $\alpha_{\text {min }}$ and $\beta_{\text {min }}$ obtained from the analysis based on the fits with standard deviations for all parameters less than $10 \%$. The cut-off at 2 of $\alpha$ in the first plot is an artifact of our fitting method.
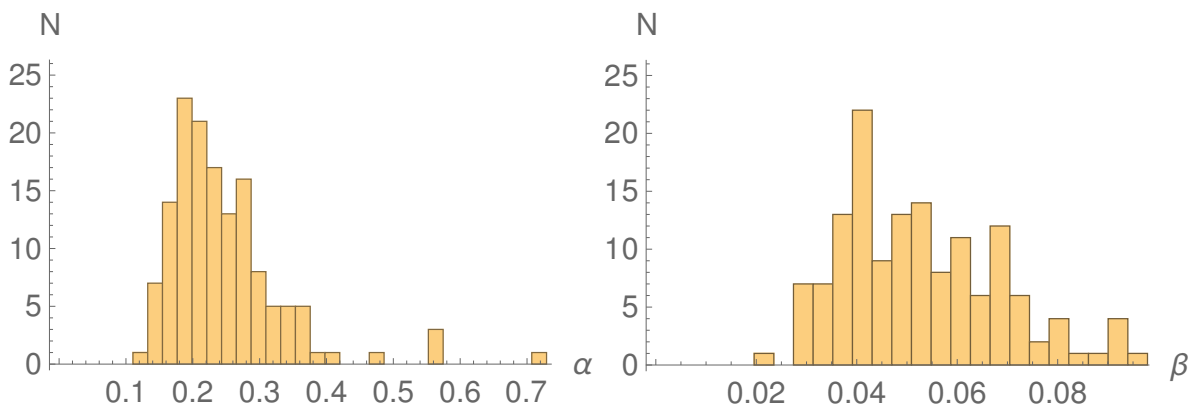

Figure 2.6: Histograms of the values of $\alpha$ and $\beta$ for the deaths time-series. 


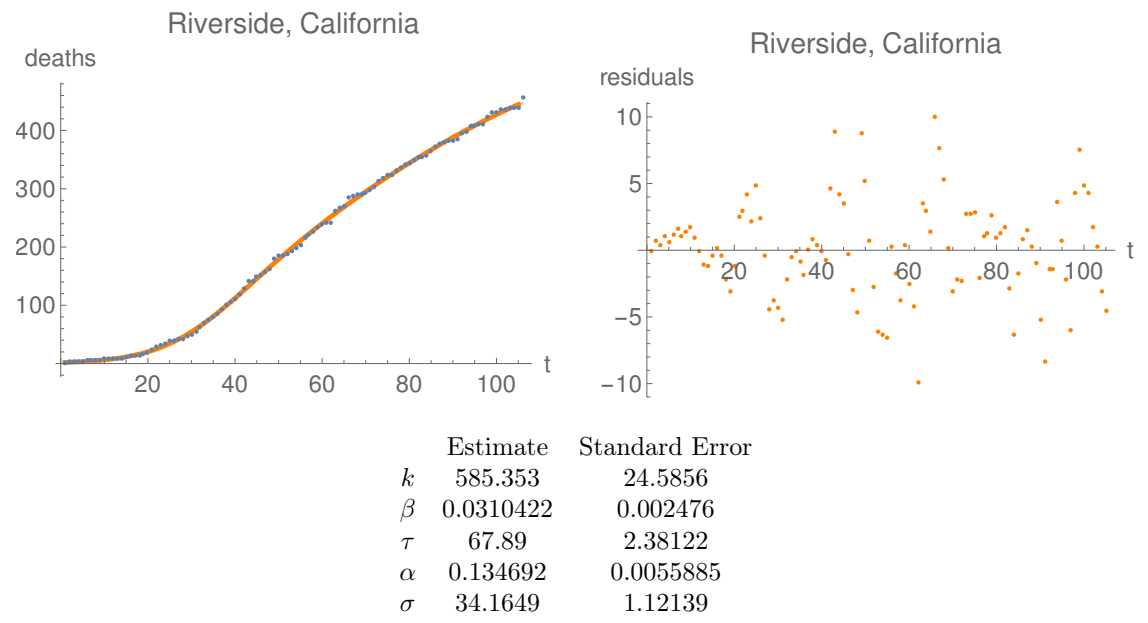

Figure 2.7: Plots of the time series for the best fits before June 30, 2020, and the fit (left), as well as the residuals (right) of the fit for the deaths time-series with the second smallest value of $\alpha$, namely Riverside, California.

It should be admitted that our analysis gives unambiguous results only for these time series where a mathematically satisfactory fit to the time series has been found, and might be biased by the requirement that the extinction rate is smaller than half of the initial growth rate. It is therefore justified to question the universal validity of our findings, even more so because of the ad-hoc character of the curve (1.1).

\section{A The growth rate}

Consider an interval of data $\left\{x_{i_{1}}, \cdots, x_{i_{1}+k}\right\}$ describing the number of infectious individuals in $k+1$ consecutive days. (We expect that the numbers $x_{i}$ are proportional to the number of confirmed cases at the beginning of the epidemic. This is relevant for our interpretation in the main body of this paper, but it is irrelevant for the considerations in this section where $x_{i}$ denotes, by definition, the number of infectious individuals.) Suppose that the data are well approximated by the exponential curve

$$
x_{i}=x_{i_{1}} e^{\alpha\left(i-i_{1}\right)}, \quad i=i_{1}, i_{1}+1, \ldots, i_{1}+k .
$$

Let $k_{0}$ denote the number of days during which an individual is infectious. We suppose that the probability of infecting someone is constant during this period. At day $i_{1}+k$ with $k \leq k_{0}$, thus after $k$ days, each individual which is infections at day $i_{1}$ will lead to $e^{\alpha k}$ infected individuals, hence will have infected

$$
e^{\alpha k}-1
$$

individuals.

After $k_{0}$ days the individual is removed from the set of infectious individuals, hence the remaining number of infectious individuals equals

$$
R_{0}:=e^{\alpha k_{0}}-1
$$


medRxiv preprint doi: https://doi.org/10.1101/2020.08.24.20181214; this version posted August 30, 2020. The copyright holder for this preprint (which was not certified by peer review) is the author/funder, who has granted medRxiv a license to display the preprint in It is made available under a CC-BY-NC-ND 4.0 International license .
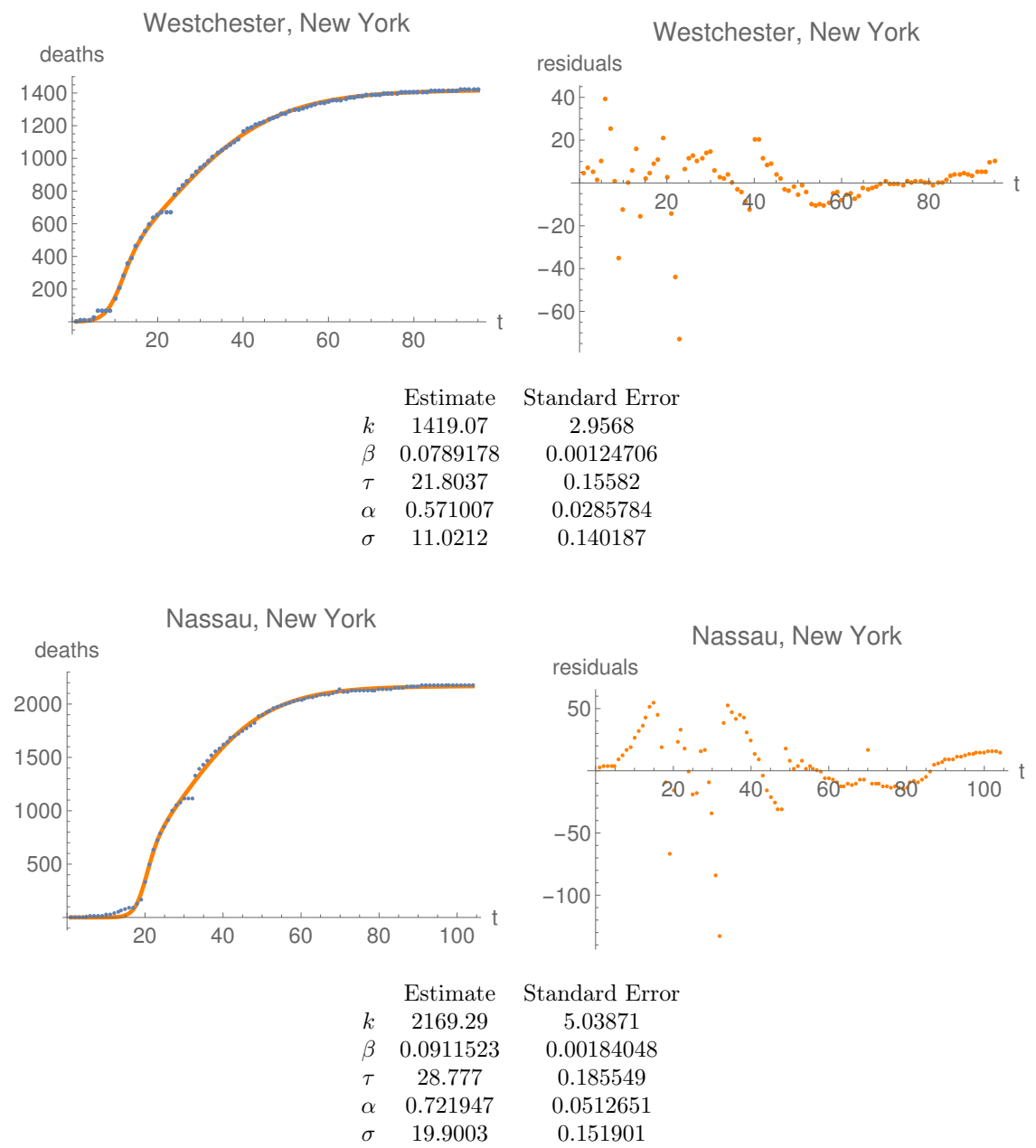

Figure 2.8: Plots of the time series for the best fits before June 30, 2020, and the fit (left), as well as the residuals (right) of the fit for the deaths time-series with largest values of $\alpha$ (Westchester and Nassau Counties, both New York State). One could fine-tune both fits by smoothing out the jumps, which drive the fit down and therefore the residuals up. 
medRxiv preprint doi: https://doi.org/10.1101/2020.08.24.20181214; this version posted August 30, 2020. The copyright holder for this preprint (which was not certified by peer review) is the author/funder, who has granted medRxiv a license to display the preprint in It is made available under a CC-BY-NC-ND 4.0 International license .

It follows that the law (A.1) persists when $e^{\alpha k_{0}}$ is much larger than one. On the other hand, (A.1) will break down when $e^{\alpha k_{0}}$ is of order one.

Within this model, an epidemic dies out if the number of infectious individuals after $k_{0}$ days is smaller than 1:

$$
e^{\alpha k_{0}}-1<1 \quad \Longleftrightarrow \quad e^{\alpha k_{0}}<2 \quad \alpha k_{0}<\ln 2 \approx 0.69 .
$$

Thus, an epidemic time-series for which

$$
k_{0} \leq \frac{\ln 2}{\alpha}
$$

never follows the exponential law (A.1) for more than $k_{0}$ days.

Equivalently, no epidemic with the exponential law (A.1) will be observed with a parameter $\alpha$ such that

$$
\alpha \leq \alpha_{\min }:=\frac{\ln 2}{k_{0}} .
$$

We conclude that the time $k_{0}$ during which an individual is infectious can be determined by measuring the threshold number $\alpha_{\min }$.

Note that the equality case in (A.4) corresponds to the doubling time of the epidemic. Hence, in this simple model, the time during which an individual is infectious is smaller than or equal the smallest observed doubling time of the epidemic.

\section{B $R_{0}$ for selected time-series}


medRxiv preprint doi: https://doi.org/10.1101/2020.08.24.20181214; this version posted August 30, 2020. The copyright holder for this preprint (which was not certified by peer review) is the author/funder, who has granted medRxiv a license to display the preprint in

It is made available under a CC-BY-NC-ND 4.0 International license .

\begin{tabular}{|c|c|c|c|c|c|c|c|c|}
\hline & Country & $\mathrm{R}_{0}$ & & Country & $\mathrm{R}_{0}$ & & Country & $\mathrm{R}_{0}$ \\
\hline 1 & Cumberland, New Jersey & $1.00 \pm 0.06$ & 56 & Snohomish, Washington & $2.26 \pm 0.09$ & 111 & Collin, Texas & $3.52 \pm 0.29$ \\
\hline 2 & San Juan, New Mexico & $1.01 \pm 0.07$ & 57 & Estonia & $2.27 \pm 0.20$ & 112 & Marshall, lowa & $3.53 \pm 0.29$ \\
\hline 3 & Mexico & $1.15 \pm 0.06$ & 58 & Saginaw, Michigan & $2.31 \pm 0.20$ & 113 & Jefferson, Colorado & $3.55 \pm 0.29$ \\
\hline 4 & Russia & $1.240 \pm 0.028$ & 59 & Fairfield, Connecticut & $2.32 \pm 0.19$ & 114 & Somerset, New Jersey & $3.57 \pm 0.35$ \\
\hline 5 & Sweden & $1.24 \pm 0.06$ & 60 & Lake, Indiana & $2.32 \pm 0.15$ & 115 & Osceola, Florida & $3.57 \pm 0.26$ \\
\hline 6 & Denmark & $1.29 \pm 0.06$ & 61 & Calhoun, Michigan & $2.32 \pm 0.22$ & 116 & Sandoval, New Mexico & $3.69 \pm 0.28$ \\
\hline 7 & Harford, Maryland & $1.29 \pm 0.08$ & 62 & Mercer, New Jersey & $2.34 \pm 0.18$ & 117 & Delaware, Pennsylvania & $3.78 \pm 0.30$ \\
\hline 8 & Kent, Michigan & $1.29 \pm 0.08$ & 63 & Anne Arundel, Maryland & $2.34 \pm 0.18$ & 118 & Cuyahoga, Ohio & $3.79 \pm 0.31$ \\
\hline 9 & Los Angeles, California & $1.31 \pm 0.09$ & 64 & San Mateo, California & $2.35 \pm 0.21$ & 119 & Brown, Wisconsin & $3.8 \pm 0.4$ \\
\hline 10 & Indonesia & $1.33 \pm 0.08$ & 65 & Rockingham, Virginia & $2.38 \pm 0.19$ & 120 & Berks, Pennsylvania & $3.79 \pm 0.22$ \\
\hline 11 & St. Clair, Illinois & $1.44 \pm 0.13$ & 66 & Pima, Arizona & $2.39 \pm 0.16$ & 121 & St. Louis, Missouri & $3.80 \pm 0.28$ \\
\hline 12 & Cuba & $1.46 \pm 0.06$ & 67 & Washington, Oregon & $2.39 \pm 0.12$ & 122 & Berkshire, Massachusetts & $3.83 \pm 0.27$ \\
\hline 13 & Hungary & $1.51 \pm 0.07$ & 68 & Singapore & $2.42 \pm 0.14$ & 123 & Middlesex, Connecticut & $3.9 \pm 0.4$ \\
\hline 14 & Rock Island, Illinois & $1.56 \pm 0.14$ & 69 & Montgomery, Pennsylvania & $2.44 \pm 0.11$ & 124 & Middlesex, New Jersey & $3.9 \pm 0.4$ \\
\hline 15 & Guinea & $1.59 \pm 0.11$ & 70 & Salt Lake, Utah & $2.46 \pm 0.18$ & 125 & Lebanon, Pennsylvania & $3.9 \pm 0.4$ \\
\hline 16 & Geauga, Ohio & $1.59 \pm 0.13$ & 71 & Norway & $2.46 \pm 0.12$ & 126 & Latvia & $3.94 \pm 0.21$ \\
\hline 17 & Serbia & $1.60 \pm 0.07$ & 72 & Pierce, Washington & $2.53 \pm 0.15$ & 127 & Victoria, Australia & $3.98 \pm 0.19$ \\
\hline 18 & King, Washington & $1.61 \pm 0.07$ & 73 & Spain & $2.56 \pm 0.11$ & 128 & Orange, New York & $4.0 \pm 0.4$ \\
\hline 19 & Chester, Pennsylvania & $1.64 \pm 0.10$ & 74 & Burkina Faso & $2.60 \pm 0.22$ & 129 & Summit, Utah & $4.05 \pm 0.34$ \\
\hline 20 & Essex, Massachusetts & $1.67 \pm 0.08$ & 75 & Bartow, Georgia & $2.60 \pm 0.24$ & 130 & Tallapoosa, Alabama & $4.1 \pm 0.4$ \\
\hline 21 & Howard, Maryland & $1.67 \pm 0.17$ & 76 & Camden, New Jersey & $2.62 \pm 0.14$ & 131 & Allegheny, Pennsylvania & $4.11 \pm 0.24$ \\
\hline 22 & Ukraine & $1.68 \pm 0.08$ & 77 & Romania & $2.63 \pm 0.11$ & 132 & Thailand & $4.13 \pm 0.23$ \\
\hline 23 & Cherokee, Georgia & $1.69 \pm 0.14$ & 78 & Nassau, New York & $2.64 \pm 0.09$ & 133 & New York, New York & $4.19 \pm 0.32$ \\
\hline 24 & Suffolk, Massachusetts & $1.69 \pm 0.08$ & 79 & Germany & $2.67 \pm 0.06$ & 134 & Black Hawk, lowa & $4.22 \pm 0.21$ \\
\hline 25 & Norfolk, Massachusetts & $1.70 \pm 0.08$ & 80 & Czechia & $2.71 \pm 0.13$ & 135 & Kandiyohi, Minnesota & $4.2 \pm 0.4$ \\
\hline 26 & Middlesex, Massachusetts & $1.70 \pm 0.05$ & 81 & Prince George's, Maryland & $2.71 \pm 0.27$ & 136 & Livingston, Michigan & $4.3 \pm 0.4$ \\
\hline 27 & India & $1.70 \pm 0.09$ & 82 & United Kingdom & $2.72 \pm 0.11$ & 137 & Philippines & $4.49 \pm 0.30$ \\
\hline 28 & Dauphin, Pennsylvania & $1.74 \pm 0.12$ & 83 & Panama & $2.76 \pm 0.22$ & 138 & Dutchess, New York & $4.57 \pm 0.28$ \\
\hline 29 & Ontario, Canada & $1.77 \pm 0.07$ & 84 & Bangladesh & $2.78 \pm 0.20$ & 139 & Wayne, Michigan & $4.60 \pm 0.20$ \\
\hline 30 & San Francisco, California & $1.77 \pm 0.11$ & 85 & Denton, Texas & $2.78 \pm 0.21$ & 140 & Ocean, New Jersey & $4.7 \pm 0.4$ \\
\hline 31 & Belarus & $1.79 \pm 0.04$ & 86 & Webb, Texas & $2.82 \pm 0.19$ & 141 & Netherlands & $4.8 \pm 0.5$ \\
\hline 32 & Litchfield, Connecticut & $1.80 \pm 0.11$ & 87 & Palm Beach, Florida & $2.92 \pm 0.24$ & 142 & Pike, Pennsylvania & $4.8 \pm 0.5$ \\
\hline 33 & Belgium & $1.85 \pm 0.07$ & 88 & Fulton, Georgia & $2.92 \pm 0.29$ & 143 & Genesee, Michigan & $4.88 \pm 0.34$ \\
\hline 34 & Poland & $1.86 \pm 0.07$ & 89 & Richland, South Carolina & $2.94 \pm 0.23$ & 144 & Austria & $5.02 \pm 0.24$ \\
\hline 35 & Cobb, Georgia & $1.86 \pm 0.14$ & 90 & Philadelphia, Pennsylvania & $2.99 \pm 0.27$ & 145 & Washtenaw, Michigan & $5.05 \pm 0.34$ \\
\hline 36 & DeKalb, Georgia & $1.87 \pm 0.16$ & 91 & Cyprus & $3.00 \pm 0.25$ & 146 & Jefferson, Louisiana & $5.08 \pm 0.25$ \\
\hline 37 & McKinley, New Mexico & $1.91 \pm 0.09$ & 92 & Oakland, Michigan & $3.06 \pm 0.13$ & 147 & Morris, New Jersey & $5.1 \pm 0.4$ \\
\hline 38 & Greece & $1.92 \pm 0.09$ & 93 & Italy & $3.07 \pm 0.07$ & 148 & Miami-Dade, Florida & $5.4 \pm 0.4$ \\
\hline 39 & Alameda, California & $1.99 \pm 0.14$ & 94 & Houston, Georgia & $3.09 \pm 0.31$ & 149 & Switzerland & $5.38 \pm 0.28$ \\
\hline 40 & Douglas, Georgia & $2.00 \pm 0.18$ & 95 & Scott, lowa & $3.09 \pm 0.23$ & 150 & Croatia & $5.5 \pm 0.5$ \\
\hline 41 & Scott, Mississippi & $2.01 \pm 0.16$ & 96 & District of Columbia & $3.10 \pm 0.25$ & 151 & Essex, New Jersey & $5.60 \pm 0.35$ \\
\hline 42 & Adams, Pennsylvania & $2.04 \pm 0.20$ & 97 & New Haven, Connecticut & $3.15 \pm 0.13$ & 152 & St. Tammany, Louisiana & $5.6 \pm 0.5$ \\
\hline 43 & Santa Clara, California & $2.04 \pm 0.14$ & 98 & Carbon, Pennsylvania & $3.16 \pm 0.25$ & 153 & Channel Islands, United Kingdom & $5.7 \pm 0.5$ \\
\hline 44 & Ireland & $2.06 \pm 0.14$ & 99 & De Soto, Louisiana & $3.17 \pm 0.30$ & 154 & Bergen, New Jersey & $5.9 \pm 0.5$ \\
\hline 45 & St. Joseph, Indiana & $2.06 \pm 0.19$ & 100 & Trumbull, Ohio & $3.23 \pm 0.30$ & 155 & Luxembourg & $5.9 \pm 0.4$ \\
\hline 46 & Dominican Republic & $2.07 \pm 0.17$ & 101 & Hampden, Massachusetts & $3.25 \pm 0.28$ & 156 & Monroe, Pennsylvania & $5.98 \pm 0.26$ \\
\hline 47 & Ulster, New York & $2.08 \pm 0.16$ & 102 & Boone, Indiana & $3.28 \pm 0.30$ & 157 & Lafourche, Louisiana & $6.3 \pm 0.4$ \\
\hline 48 & Finland & $2.12 \pm 0.14$ & 103 & Broward, Florida & $3.28 \pm 0.27$ & 158 & Hamilton, Indiana & $7.0 \pm 0.5$ \\
\hline 49 & Lithuania & $2.13 \pm 0.16$ & 104 & Waukesha, Wisconsin & $3.30 \pm 0.33$ & 159 & Northampton, Pennsylvania & $7.5 \pm 0.7$ \\
\hline 50 & Turkey & $2.16 \pm 0.06$ & 105 & Monmouth, New Jersey & $3.31 \pm 0.14$ & 160 & Lehigh, Pennsylvania & $7.61 \pm 0.35$ \\
\hline 51 & Leake, Mississippi & $2.16 \pm 0.14$ & 106 & Macomb, Michigan & $3.31 \pm 0.17$ & 161 & Luzerne, Pennsylvania & $9.9 \pm 0.4$ \\
\hline 52 & Moldova & $2.17 \pm 0.15$ & 107 & US & $3.38 \pm 0.09$ & 162 & Korea, South & $12.2 \pm 0.9$ \\
\hline 53 & Crisp, Georgia & $2.18 \pm 0.17$ & 108 & Charles, Maryland & $3.40 \pm 0.30$ & 163 & Stearns, Minnesota & $13.5 \pm 1.2$ \\
\hline 54 & York, Pennsylvania & $2.20 \pm 0.10$ & 109 & Guinea-Bissau & $3.45 \pm 0.31$ & & & \\
\hline 55 & Washington, lowa & $2.21 \pm 0.11$ & 110 & Suffolk, New York & $3.51 \pm 0.17$ & & & \\
\hline
\end{tabular}

Table B.1: The initial rate of propagation $R_{0}$ for time series with a relative standard deviation smaller than $10 \%$, ordered according to the value of $R_{0}$. Strictly speaking, the numbers given are lower bounds for $R_{0}$, but we expect them to be close to the correct values. 


\section{Remarks on the "double-logistic" function}

Consider the function

$$
I(t)=k \times \frac{1}{1+c_{1} e^{-b_{1} t}} \times \frac{1}{1+c_{2} e^{-b_{2} t}},
$$

with

$$
k, c_{1}, c_{2}, b_{1}, b_{2}>0 .
$$

Before trying to fit $I$ to some time series, one needs to resolve the degeneracy related to the symmetry $\left(b_{1}, c_{1}\right) \leftrightarrow\left(b_{2}, c_{2}\right)$, This can be removed by requiring that

$$
b_{1} \leq b_{2} .
$$

The case $b_{1}=b_{2}$ would have required special attention, but in all the fits considered this case has never occurred, so we will from now on assume

$$
b_{1}<b_{2} .
$$

One can write $c_{1}$ as $e^{-b_{1} \sigma}$ and $c_{2}$ as $e^{-b_{2} \tau}$, which brings (C.1) to the form

$$
I(t)=k \times \frac{1}{1+e^{-b_{1}(t-\sigma)}} \times \frac{1}{1+e^{-b_{2}(t-\tau)}} .
$$

The initial growth rate of $I$ is $\alpha:=b_{1}+b_{2}$, while the final extinction rate is

$$
\beta:=b_{1} .
$$

Renaming thus $b_{1}$ to $\beta$ we can write

$$
0<b_{2}=\alpha-b_{1} \equiv \alpha-\beta,
$$

which leads to the following form of (C.4):

$$
I(t)=k \times \frac{1}{1+e^{-\beta(t-\sigma)}} \times \frac{1}{1+e^{-(\alpha-\beta)(t-\tau)}} .
$$

The first inequality in (C.6) shows that $\alpha>\beta$ : equivalently, a necessary condition for $I$ to provide a good description of the epidemic the initial growth rate must be larger than the final extinction rate. We will see shortly that in fact we must have the inequality (C.8).

We emphasise that the above renaming of the exponents $b_{1}$ and $b_{2}$ requires that the exponent which has been renamed to $\beta$ should be smaller than the exponent that has been renamed to $\alpha-\beta$. Hence, if a fit of the data to the function (C.7) has been made, and if the parameters so determined are such that the parameter which was thought to be $\alpha-\beta$ is smaller than the parameter which was thought to be $\beta$, then the parameter which has been renamed to $\alpha-\beta$ should actually be $\beta$, and the parameter that has been renamed to $\beta$ should be $\alpha-\beta$.

This somewhat confusing discussion leads to a more stringent restriction for $I$ to provide a good fit to the data: Since $\beta \leq \alpha-\beta$ we must have

$$
\beta \leq \frac{\alpha}{2} .
$$


This shows that no good fit to the data can be found if (C.8) fails.

The above is closely related to the question of uniqueness of the parameters in (C.7). Here the question is, for what sets of parameters $(\alpha, \beta, \sigma, \tau)$ and $\left(\alpha^{\prime}, \beta^{\prime}, \sigma^{\prime}, \tau^{\prime}\right)$ it holds for all $t$

$$
\frac{1}{1+e^{-\beta(t-\sigma)}} \times \frac{1}{1+e^{-(\alpha-\beta)(t-\tau)}}=\frac{1}{1+e^{-\beta^{\prime}\left(t-\sigma^{\prime}\right)}} \times \frac{1}{1+e^{-\left(\alpha^{\prime}-\beta^{\prime}\right)\left(t-\tau^{\prime}\right)}} .
$$

Equivalently,

$$
\left(1+e^{-\beta(t-\sigma)}\right)\left(1+e^{-(\alpha-\beta)(t-\tau)}\right)=\left(1+e^{-\beta^{\prime}\left(t-\sigma^{\prime}\right)}\right)\left(1+e^{-\left(\alpha^{\prime}-\beta^{\prime}\right)\left(t-\tau^{\prime}\right)}\right),(C
$$

which is the same as

$$
\begin{aligned}
& e^{-\beta(t-\sigma)}+e^{-(\alpha-\beta)(t-\tau)}+e^{-\alpha t+\beta \sigma+(\alpha-\beta) \tau} \\
& \quad=e^{-\beta^{\prime}\left(t-\sigma^{\prime}\right)}+e^{-\left(\alpha^{\prime}-\beta^{\prime}\right)\left(t-\tau^{\prime}\right)}+e^{-\alpha^{\prime} t+\beta^{\prime} \sigma^{\prime}+\left(\alpha^{\prime}-\beta^{\prime}\right) \tau^{\prime}} .
\end{aligned}
$$

By comparing the fastest growing terms on both sides for $t \rightarrow-\infty$ one finds

$$
\alpha=\alpha^{\prime} .
$$

From the subleading exponential terms one obtains

$$
\text { either } \beta=\beta^{\prime} \text { or } \beta=\alpha^{\prime}-\beta^{\prime} \text { (or both). }
$$

The first case leads to the obvious solution $(\alpha, \beta, \sigma, \tau)=\left(\alpha^{\prime}, \beta^{\prime}, \sigma^{\prime}, \tau^{\prime}\right)$, while the second leads to

$$
\tau=\sigma^{\prime}, \quad \sigma=\tau^{\prime} .
$$

We have thus shown that the sets of parameters

$$
(\alpha, \beta, \sigma, \tau) \text { and }(\alpha, \alpha-\beta, \tau, \sigma)
$$

give the same function $I$, and that this is the only nontrivial possibility

In order to remove this degeneracy, within our fitting procedure we enforce the inequality

$$
\tau \geq \sigma .
$$

If a fit is found saturating the equality we repeat the procedure with the reverse inequality in place.

\section{References}

[1] P. T. Chruściel, S. J. Szybka, medRxiv:2020.05.22.20098350 .

[2] F. Richards, Jour. Exp. Botany 10, 290 (1959).

[3] L. Ferretti, et al., Science 368 (2020).

[4] X. He, et al., Nature Medicine 26, 672 (2020). 